\title{
POLÍTICAS DE AÇÃO AFIRMATIVA COMO ESTRATÉGIA DE CONSTRUÇÃO DA IGUALDADE RACIAL
}

\author{
Zélia Amador de Deus ${ }^{1}$
}

\begin{abstract}
Resumo: Este escrito objetiva mostrar as Ações Afirmativas no quadro das legislações internacionais e apontar sua principal função que é a reparação aos danos causados pelo racismo às populações por ele vitimadas. Para a realização desta tarefa, utilizei como método a autobiografia etnográfica e, em consonância com ela, analisei os dispositivos legais pertinentes ao tema proposto. Constatei que o racismo começa a ser preocupação legal nos países europeus após a Segunda Grande Guerra e, a maneira como as legislações internacionais de combate ao racismo se apresentam só foi possível graças ao protagonismo dos grupos vitimizados pelo racismo. A atuação deles deu caráter estratégico ao conjunto legal e abriu caminhos para a construção da igualdade racial.
\end{abstract}

Palavras-chave: Políticas de ação afirmativa; Igualdade Racial; Legislações Internacionais; Conferência de Durban; Reparação.

\section{AFFIRMATIVE ACTION POLICIES AS A STRATEGY TO CONSTRUCT RACIAL} EQUALITY

\begin{abstract}
This paper aims to show the Affirmative Actions within the framework of international legislation and to point out its main function, which is to repair the damages caused by racism to the populations it victimizes. For the accomplishment of this task, I used ethnographic autobiography as a method and, in consonance with it; I analyzed the legal dispositions pertinent to the proposed theme. I found that racism became a legal concern in European countries after the Second World War, and the way in which international legislation to combat racism is presented was only possible thanks to the protagonism of groups victimized by racism. Their performance gave a strategic character to the legal set and paved the way for the construction of racial equality.
\end{abstract}

Key-words: Affirmative action policies; Racial equality; International Legislation; Conference of Durban. Repair.

\section{POLITIQUES D'ACTION AFFIRMATIVE COMME UNE STRATÉGIE POUR CONSTRUIRE L'ÉGALITÉ RACIALE}

Résumé: Ce document a pour objectif de présenter les Actions Affirmative dans le cadre de la législation internationale et de souligner sa fonction principale, qui consiste à réparer les dommages causés par le racisme aux populations dont il est victime. Pour la réalisation de cette tâche, j'ai utilisé comme méthode l'autobiographie ethnographique et, conformément à celle-ci, j'ai analysé les dispositions juridiques pertinentes pour le thème proposé. J'ai constaté que le racisme est une préoccupation juridique a partir des pays européens après la Seconde Guerre Mondiale et, la forme comme des législations internationales de combat au racisme se présenté seul été possible grâce au protagonisme des groupes victimes du racisme. Leurs performances ont conféré un caractère stratégique à l'ensemble juridique et ouvert la voie à la construction de l'égalité raciale.

\footnotetext{
${ }^{1}$ Letróloga, é doutora em Ciências Sociais pela Universidade Federal do Pará (UFPA), onde é professora no Instituto de Ciências da Arte (ICA/UFPA).E-mail: zeliamador@gmail.com
} 
Mots-clés: Politiques d'action affirmative; Égalité Raciale; Législations Internationales; Conférence de Durban. Réparation.

\section{POLÍTICAS DE ACIÓN AFIRMATIVA COMO ESTRATEGIA DE CONSTRUCIÓN DE LA IGUALDAD RACIAL}

Resumen: Este escrito tiene como objetivo mostrar las Acciones Afirmativas em el marco de las legislaciones internacionales y apuntar su principal función que es la reparación a los daños causados por el racismo a las poblaciones por él victimadas. Para la realización de esta tarea, utilicé como método la autobiografía etnográfica y, en consonancia con ella, analizé los dispositivos legales pertinentes al tema propuesto. He constatado que el racismo comienza a ser preocupación legal en los países europeos después de la Segunda Guerra Mundial y la manera en que las legislaciones internacionales de combate al racismo se presentan sólo fue posible gracias al protagonismo de los grupos victimizados por el racismo. La actuación de ellos dio carácter estratégico al conjunto legal y abrió caminos para la construcción de la igualdad racial.

Palabras-clave: Políticas de acción afirmativa; Igualdad Racial; Legislaciones internacionales; Conferencia de Durban. Reparación.

\section{PRIMEIRAS PALAVRAS}

Neste momento, inicio minha fala reiterando o que antes foi afirmado por Luis Alberto Gonçalves: "A Fúlvia ${ }^{2}$ faz falta”, pois falar dos trinta anos de Raça Negra e Educação sem lembrar-se de Fúlvia é impossível. Após esta reflexão, inicio minha participação esclarecendo que falo não apenas como professora da academia, mas também a partir das experiências adquiridas na luta contra o racismo. Seguindo a postura metodológica de Fischer (2016), posso dizer que meu texto tem o caráter de uma autobiografia etnográfica, qual seja, uma autobiografia que discute de modo crítico e minucioso os aspectos socioculturais do qual minha trajetória de vida é indissociável.

Neste sentido, é deste lugar que enfoco as relações raciais no Brasil contemporâneo para falar do papel do Movimento Negro para a construção das Políticas de Ação Afirmativa e de todo o processo que o Estado brasileiro denomina de "Políticas de Promoção da Igualdade Racial" e que nós, do Movimento Negro, chamamos de combate ao Racismo e Eliminação da Discriminação Racial. Desse modo, creio haver estabelecido o lugar de onde falo. Significa dizer que não falo na condição de espectadora, mas falo como parte envolvida no processo.

\footnotetext{
${ }^{2}$ Fúlvia Rosemberg. Pesquisadora da Fundação Carlos Chagas, docente titular da Pontifícia Universidade Católica de São Paulo (PUC-SP). Especializou-se nos estudos das relações raciais, relações de gênero, relações de idade e políticas de ação afirmativa. Fúlvia esteve envolvida no processo de organização do Seminário "Raça negra e Educação" há 31 anos.
} 
Nesta perspectiva, falar de Política de Ação Afirmativa é falar de um processo de luta aquém dos trinta anos que estamos aqui para celebrar, não podemos esquecer que, em muitos lugares, foi necessário que os herdeiros da diáspora africana chegassem às Academias para forjar espaços. A experiência cotidiana de opressão os acompanhou, esses, não entraram sozinhos para a Academia ou para qualquer lugar que ocupem. Não costumam andar sozinhos. Carregam consigo, além de sua história de vida, a história de seus ancestrais. A marca dessa história está em seus corpos, os acompanha em qualquer lugar a que vão. Mesmo que eles queiram esquecer, não lhes é permitido. Haverá sempre alguém disposto a mostrar-lhes, sem a maior cerimônia - "É um negro!" - Isso, na melhor das hipóteses. Às vezes, no embate, logo vem a agressão - "Não passa de um negro!" - Aqui, lembro de Frantz Fanon (1983, p. 93):

Então, desorientado, incapaz de ser livre como o outro, o Branco, que, impiedosamente me aprisiona, eu me distanciei de meu ser, para bem longe, tornando-me um objeto. O que era para mim, senão uma separação uma extirpação, uma hemorragia que coagulava sangue negro sobre todo o meu corpo? Portanto, não queria esta consideração, esta temática. "Queria apenas ser um homem entre outros homens".

Com efeito, volto às políticas de ação afirmativa, particularmente cotas para negros(as) na universidade. A presença negra nas universidades - ao contrário do que pensaram os signatários dos dois manifestos anticotas, diziam que as "cotas iriam acirrar o racismo" - pode se tornar um motor gerador de um dinamismo interno nas academias, capaz de gerar um futuro promissor. Para tanto, é necesario que o mecanismo do sistema de 'cotas' para negros nas Instituições de Ensino Superior (IES) atinja o objetivo de aumentar essa presença negra no espaço acadêmico visando a desconstruir o discurso dominante. Sem sombra de dúvidas, essa presença aumentou e isso pode ser mensurado pelo número de coletivos de negros e negras existentes nas universidades federais, hoje.

Portanto, enegrecer o espaço acadêmico, visando a aumentar os números de estudos e pesquisas que tratem da questão racial e que busquem encontrar saídas para a sociedade por meio de estudos e pesquisas que possam ancorar a eliminação do Racismo e da Discriminação Racial, foi a grande tarefa desempenhada pelo Movimento Negro, que culminou com a aprovação do Projeto de Lei n. ${ }^{\circ}$ 12.711, de 29 de agosto de 
2012. Nesta linha de raciocínio, digo que o Movimento Negro foi sagaz, no sentido de aproveitar o contexto pós-Durban e, daquele momento em diante, manter o foco aproveitando-se de todas as brechas e fendas abertas pelos mecanismos criados pelos brancos e para os brancos. Aqui, me refiro à Declaração Universal dos Direitos Humanos, trazendo à tona a criação pela Organização das Nações Unidas (ONU) do Direito Internacional dos Direitos Humanos.

Ainda nessa linha de raciocínio, ouso dizer que a Marcha de 1995, "300 anos de Zumbi pela cidadania e pela vida", encontra-se ancorada na cobrança do papel do Estado brasileiro em garantir a execução de Políticas Públicas de Combate ao Racismo e a Eliminação da Discriminação Racial. Isso sem perder de vista a base legítima dessa cobrança, a saber, a Convenção da ONU pela Eliminação de todas as Formas de Discriminação Racial (CERD), sobretudo com o apoio do preâmbulo do referido instrumento.

\section{AÇÃO AFIRMATIVA E DIREITO INTERNACIONAL DOS DIREITOS HUMANOS}

A partir da Declaração Universal dos Direitos Humanos, começa a se desenvolver o Direito Internacional dos Direitos Humanos, mediante a adoção de inúmeros instrumentos internacionais de proteção. Aqui, cabe ressaltar que a Declaração de 1948 introduz a chamada concepção contemporânea de Direitos Humanos, marcados pela universalidade e indivisibilidade desses direitos. Universalidade porque clama pela extensão universal dos Direitos Humanos, a partir do entendimento de que a condição de pessoa é o requisito único para a titularidade de direitos, considerando o ser humano como um ser essencialmente moral, dotado de unicidade existencial e dignidade. Indivisibilidade porque o catálogo dos direitos civis e políticos é conjugado ao catálogo dos direitos econômicos, sociais e culturais. O processo de universalização dos Direitos Humanos permitiu a formação de um sistema internacional desses direitos. Esse sistema é integrado por tratados internacionais voltados à proteção de direitos fundamentais.

A primeira fase da proteção dos Direitos Humanos foi marcada pela tônica da proteção geral com base na igualdade formal. Essa fase expressa o temor à diferença que no nazismo havia sido orientada para o extermínio. Aqui, é importante ressaltar que os horrores da Segunda Guerra Mundial provocaram o temor da repetição de um novo 
holocausto, o que vai inspirar a Declaração Universal de Direitos Humanos. Não é demais lembrar que o que aconteceu durante o período do nazismo já houvera acontecido, quando da colonização europeia das Américas e do processo de escravização dos povos indígenas e dos africanos. Contudo, a questão que se põe agora é que, antes, as vítimas eram os "outros" e o solo não era o europeu. O horror do extermínio nazista se explica pela possibilidade maior de um processo de identificação com o "outro" exterminado. Razão pela qual a diferença se faz tão temida e levará algum tempo para ser assimilada.

Contudo, com o passar do tempo, percebe-se que tratar o indivíduo de forma abstrata e genérica não é suficiente. Cada indivíduo, para ter os direitos fundamentais garantidos, tem que ser entendido em sua particularidade e especificidade. Isso porque determinadas violações de direitos carecem de medidas específicas para serem reparadas. Caso contrário corre-se o risco de a medida não alcançar o sujeito de direitos em sua plenitude. Significa dizer que, a partir desse ponto de vista, a diferença que fora utilizada para que se aniquilasse, inclusive o direito à vida, assumirá outra dimensão. Ou seja, nesse novo contexto, a diferença não mais deverá ser utilizada para a aniquilação de direitos, mas, ao contrário, deve ser entendida e levada em consideração para a promoção de direitos. Nessa perspectiva, ao lado da promoção da igualdade, surge, como direito fundamental, o Direito à Diferença. Importa o respeito à diferença e à diversidade, o que assegurará, a determinados grupos, um tratamento especial.

A partir desse momento, faz-se necessário a especificação do sujeito de direito que passa a ser visto em sua peculiaridade e particularidade. Melhor dizendo, percebe-se a necessidade de conferir a determinados grupos uma proteção especial e particularizada. Os grupos que carecem dessa proteção particularizada são os grupos vítimas de discriminações. A discriminação, suprimindo direitos fundamentais, os coloca em situação de vulnerabilidade. É nesse cenário que negros, povos indígenas, mulheres, crianças e demais grupos passarão a ser vistos nas especificidades e peculiaridades de sua condição. A cena, portanto, está pronta, para que seja adotada uma nova concepção de igualdade. Nesse caso, uma concepção substancial da igualdade, a igualdade material. 
A partir do redimensionamento do conceito de igualdade, passa-se a destacar três vertentes de igualdade. A igualdade formal - "todos são iguais perante a lei". A igualdade material correspondente ao ideal de justiça social e distributiva, orientada pelo critério socioeconômico. E a igualdade material correspondente ao ideal de justiça enquanto reconhecimento de identidades. Essa vertente de igualdade material orienta-se pelos critérios de gênero, raça, etnia, idade, orientação sexual e demais critérios que possam ter sido utilizados para justificar discriminações.

É importante ressaltar também que a igualdade material, com base no ideal de justiça enquanto reconhecimento de identidades, apresenta o caráter bidimensional da justiça: a justiça enquanto redistribuição e a justiça enquanto reconhecimento. Desse ponto de vista, a justiça só será completa em sua bidimensionalidade. Nessa perspectiva, Boaventura de Souza Santos (2006, p. 313) observa: "Uma política de igualdade que desconhece ou descaracteriza as diferenças [...] é de fato, uma política racista [...], pois o racismo tanto se afirma pela absolutização das diferenças como pela negação das diferenças".

E prossegue Boaventura (2006, p 316): “temos o direito a ser iguais sempre que a diferença nos inferioriza; temos o direito a ser diferentes sempre que a igualdade nos descaracteriza".

Retomando as estratégias, é importante dizer que é nesse novo contexto que as Nações Unidas aprovam, em 1965, a Convenção sobre a Eliminação de todas as formas de Discriminação Racial (CERD). Sobre essa Convenção e seu processo de ratificação, no Brasil, falei anteriormente. Contudo, não posso deixar de ressaltar a importância do preâmbulo da Convenção.

Considerando que a Carta das Nações Unidas baseia-se em princípios de dignidade e igualdade. Princípios inerentes a todos os seres humanos. Todos os Estados-Membros comprometem-se a tomar medidas separadas e conjuntas, em cooperação com a organização para consecução de um dos propósitos das Nações Unidas, que é promover e encorajar o respeito universal e a observância dos direitos fundamentais para todos, sem discriminação de raça, sexo, idioma ou religião. [...] Convencidos de que a existência de que a superioridade racial baseada em diferenças raciais é cientificamente falsa, moralmente condenável, socialmente injusta e perigosa, e que não existe justificação para a discriminação racial, em teoria ou na prática, em lugar algum. (ONU, 1998, p. 122) 
A Convenção também aponta para a urgência da adoção de medidas necessárias para que se elimine a discriminação racial em todas as suas formas e manifestações. E, portanto, os Estados-partes, em conjunto ou separadamente, devem envidar esforços para prevenir e combater práticas racistas. Nesse particular, não é demais lembrar que o Brasil é signatário da Convenção e que ela foi ratificada pelo Parlamento Brasileiro, em 1968. Por esse motivo, o Brasil, a partir daquele momento, assumiu o compromisso de cumprir, em relação à população negra, o disposto no documento de que é signatário, conforme se observa no item 4, do Artigo primeiro:

Não serão consideradas discriminação racial as medidas especiais tomadas com o único objetivo de assegurar o progresso adequado de certos grupos raciais ou étnicos ou de indivíduos que necessitem de proteção que possa ser necessária para proporcionar a tais grupos ou individuos igual gozo ou exercício de direitos humanos e a liberdades fundamentais, contanto que tais medidas não conduzam, em consequência, à manutenção de direitos separados para diferentes grupos raciais e não prossigam após terem atingido os seus objetivos. (ONU, 1998, p. 52)

Ressalto ainda que o Artigo primeiro do referido instrumento (ONU, 1998, p. 125) institui o conceito de discriminação como "qualquer distinção, exclusão ou preferência baseada em raça, cor, descendência, origem nacional ou etnia que tenha o propósito ou o efeito de prejudicar o reconhecimento, gozo ou exercício em pé de igualdade dos humanos e liberdades fundamentais".

Nessa perspectiva, é essa mesma lógica que servirá de inspiração para definir discriminação contra a mulher, quando foi adotada, em 1979, a Convenção sobre a Eliminação de todas as formas de Discriminação contra a Mulher $\left(\mathrm{CEDAW}^{3}\right)$, pelas Nações Unidas.

É também essa mesma lógica que irá inspirar todos os instrumentos voltados para a proteção de direitos relativos a grupos considerados em situação de vulnerabilidade, cuja diferença precise ser ressaltada e respeitada. Desse ponto de vista, crianças, adolescentes, idosos, povos indígenas e outros terão que ser entendidos, conforme suas especificidades. No âmbito do Direito Internacional dos Direitos Humanos - segmento especializado do Direito Internacional Público - há diversos

${ }^{3}$ Committee on the Elimination of Discrimination against Women.

Revista da ABPN • v. 11, Ed. Especial - Caderno Temático: Raça Negra e Educação 30 anos depois: e agora, do que mais precisamos falar? • abril de 2019, p.87-100

DOI 10.31418/2177-2770.2019.v11.c.1.p87-100 
instrumentos de proteção de direitos fundamentais que, além de proibirem toda forma de discriminação, também preveem a adoção de políticas de promoção da igualdade dos grupos tornados vulneráveis. Tais instrumentos (tratados, convenções, pactos, etc.) assumem uma dupla importância: consolidam parâmetros internacionais mínimos concernentes à proteção da dignidade humana e asseguram uma instância internacional de proteção de direitos, quando as instituições nacionais mostrarem-se falhas ou omissas.

Essa linha de raciocínio também tem inspirado os diversos estatutos de proteção de direitos violados que têm sido aprovados pelo Congresso Brasileiro. Entretanto, na medida em que se parte do princípio de que a discriminação suprime direitos fundamentais, há que se apontar a forma de combater e eliminar a discriminação. Quero dizer com isso que terá que haver definição das estratégias a serem utilizadas. Nesse sentido, no âmbito do Direito Internacional dos Direitos Humanos destacam-se três eixos: Proteção, Valorização e Promoção. Em torno desses eixos se estabelecem duas estratégias. As estratégias, portanto, têm a função de fazer com que a letra da Lei se transforme em realidade na prática cotidiana dos sujeitos. Nesta linha, se estabeleceram duas importantes estratégias: a estratégia repressivo-punitiva e a estratégia promocional.

A estratégia repressivo-punitiva tem por objetivo punir, proibir e eliminar a discriminação. Nesse particular, se incluem todas as legislações que punem a discriminação racial. Sob esta perspectiva, no que diz respeito à questão racial, no

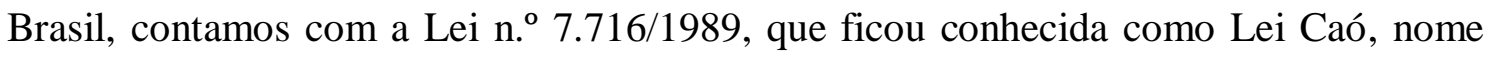
que recebeu em virtude do projeto de lei haver sido proposto pelo então Deputado Federal do PDT do Rio de Janeiro, Carlos Alberto de Oliveira. Porém, a mera existência da lei não garante o fim da discriminação. Por este motivo, é necessário que, ao lado dessa estratégia, caminhe a estratégia promocional que tem por objetivo promover, fomentar e fazer avançar a igualdade. Esta estratégia aponta para a aplicação de políticas de ação afirmativa como forma concreta de combate ao Racismo e à Discriminação Racial. Aqui, ressalto que a Lei n. ${ }^{\circ} 10.639 / 03$ se enquadra nesta estratégia. 
Entretanto, devo salientar que a III Conferência Mundial contra o Racismo, Discriminação Racial, Xenofobia e Intolerância Correlata, Conferência de Durban, 2001, tanto em sua declaração quanto em seu plano de ação aponta para uma terceira estratégia, que é o estabelecimento de "recursos e medidas eficazes de reparação, ressarcimento, e indenização e outras medidas em níveis nacional, regional e internacional" (ONU, 2011, p. 59) ${ }^{4}$. A proposta de reparação/indenização ressurge na medida em que se tratava de um pleito transnacional. Um pleito que dizia respeito aos negros, tanto do continente africano quanto aos da diáspora do continente americano. Nessa perspectiva, a estratégia de reparação entra no bojo das discussões dos Seminários Regionais Preparatórios para a Conferência mundial. Nessa linha, no Seminário Regional de São Paulo, o intelectual ativista do Movimento Negro Helio Santos, em comunicação proferida no evento nas considerações finais de sua participação, ao falar de inclusão, afirma:

A essência do debate, hoje, sobre a questão da discriminação racial que se abate sobre a população negro-descendente (pretos mais pardos) no Brasil está centrada nas políticas de reparação. O país adentrará o III milênio com um pesado déficit social. Um dos maiores do mundo. Todavia, se os estudos tomarem em conta os recortes - como demonstramos em algumas tabelas apresentadas neste texto - se evidenciarão de maneira nítida os danosos efeitos do longo escravismo brasileiro. Da mesma forma que se pode calcular os diferenciais de renda em função do binômio raça/cor, deve-se promover investimentos compensatórios no segmento negro-descendente. Trata-se - sim de medida de justiça. Todavia, é ainda por este caminho que o país alavanca todo o seu potencial humano no sentido de emergir enquanto nação próspera, onde a riqueza possa ser melhor repartida. O desafio para o século XXI passa por aí. Trata-se de desenvolver uma cultura nova, até então ausente do cenário brasileiro; a da inclusão. (Santos, 2001, p. 101-102).

Seguindo a mesma linha, no dito Seminário, o também intelectual Valter Roberto Silvério, em sua comunicação "Políticas Raciais Compensatórias: o dilema brasileiro do século XXI", assinala:

Três são os argumentos mais usuais, na atualidade, daqueles que tentam se contrapor às propostas de implantação de políticas públicas preocupadas com reparações, compensações e ou ações afirmativas que visam assegurar o acesso

\footnotetext{
${ }^{4}$ Ver a Declaração de Durban em seus itens, 98,99 e 100. E o programa de ação nos itens 157, 158 e 159 (ONU, 2011).
} 
de afrodescendentes a posições e postos estratégicos na sociedade brasileira. (Silvério, 2001, p. 123)

Seguindo a mesma trilha, o historiador baiano Ubiratan de Castro Araújo, no Seminário Regional que aconteceu na cidade de Salvador, apresentou comunicação que versou sobre o tema Reparação Moral, Responsabilidade Pública e Direito à Igualdade de Cidadãos Negros no Brasil, e diz:

A reparação deve constituir-se em um novo pacto de convívio social expresso por um programa completo, nacional, de longa duração, onde estejam definidos os compromissos da República Federativa do Brasil para a erradicação da discriminação racial e do racismo no Brasil. Para que este plano se constitua em compromisso do estado e não apenas de governo, é necessário que se crie através de lei ordinária uma Comissão Nacional de Reparação do Negro no Brasil, e que se defina a correspondente vinculação de recursos financeiros da receita da União. (Araújo, 2001, p. 322)

Ubiratan de Araújo (2001, p. 323) aponta, ainda, na dita comunicação, os objetivos que o Estado brasileiro deve buscar a alcançar, na perspectiva de um Programa Nacional de Reparação no âmbito da recuperação da Memória e História do povo negro no Brasil, encerra sua participação afirmando: "Não podemos entrar no terceiro milênio fazendo de conta que não existiu a escravidão e que o Estado brasileiro nada deve aos seus cidadãos afrodescendentes".

Ainda na linha da Reparação, o Relatório brasileiro para a Conferência de Durban refere: "criação de um fundo de reparação social gerido pelo governo e pela sociedade civil destinado a financiar políticas de cunho inclusivo no âmbito da

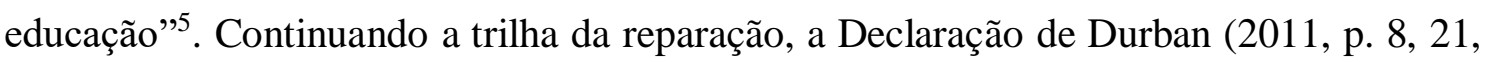
55, 58) e seu programa de ação fazem afirmações de suma importância para fundamentar a estratégia de reparação:

12 - Reconhecemos que a escravidão e o tráfico escravo, incluindo o tráfico de escravo transatlântico, foram tragédias terríveis na história da humanidade, não apenas por sua barbárie abominável, mas também em termos de sua magnitude, natureza de organização e, especialmente pela negação da essência das vítimas;

\footnotetext{
${ }^{5}$ Relatório do Comitê Nacional para a Preparação da Participação Brasileira na III Conferência Mundial das Nações Unidas contra o Racismo, Discriminação Racial, Xenofobia e Intolerância Correlata; (Durban, 31 de agosto a 07 de setembro de 2001). Brasília: Ministério da Justiça, Secretaria de Estado de Direitos Humanos, 2001, p. 30.
} 
ainda reconhecemos que a escravidão e o tráfico escravo são crimes contra a humanidade e assim devem sempre ser considerados, especialmente o tráfico de escravos transatlântico, estando entre as maiores manifestações e fontes de racismo, discriminação racial, xenofobia e intolerância correlata; e que os Africanos e afrodescendentes, Asiáticos e povos de origem asiática, bem como os povos indígenas foram e continuam a ser vítimas destes atos e de suas consequências;

13 - Reconhecemos que o colonialismo levou ao racismo, discriminação racial, xenofobia e intolerância correlata, e que os Africanos e afrodescendentes, os povos de origem asiática e os povos indígenas foram vítimas do colonialismo e continuam a ser vítimas de suas consequências. Reconhecemos o sofrimento causado pelo colonialismo e afirmamos que, onde e quando quer que tenham ocorrido, devem ser condenados e sua recorrência prevenida. Ainda lamentamos que os efeitos e a persistência dessas estruturas e práticas estejam entre os fatores que contribuem para a continuidade das desigualdades sociais e econômicas em muitas partes do mundo ainda hoje;

14 - Reconhecemos que o apartheid e o genocídio, nos termos do direito internacional, constituem crimes de lesa-humanidade e estão entre as maiores manifestações e fontes de racismo, discriminação racial, xenofobia e intolerância correlata; reconhecemos o mal não-dito e o sofrimento causado por estes atos e afirmamos que onde e quando quer que tenham ocorrido, devem ser condenados e sua recorrência prevenida;

100 - Reconhecemos e profundamente lamentamos o sofrimento e os males não-ditos infligidos a milhões de homens, mulheres e crianças como resultado da escravidão, do tráfico de escravos transatlântico, do apartheid, do colonialismo, do genocídio e das tragédias do passado. Observamos ainda que alguns Estados tiveram a iniciativa de pedirem perdão e pagarem indenização, quando apropriado, pelas graves e enormes violações perpetradas;

158 - Reconhece que estas injustiças históricas têm inegavelmente contribuído para a pobreza, subdesenvolvimento, marginalização, exclusão social, disparidades econômicas, instabilidade e insegurança que afetam muitas pessoas em diferentes partes do mundo, em espacial, nos países em desenvolvimento. A Conferência reconhece a necessidade de se desenvolverem programas para o desenvolvimento social e econômico destas sociedades e da Diáspora dentro, de uma estrutura de uma nova parceria baseada no espírito de solidariedade e respeito mútuo nas seguintes áreas: Perdão da dívida, erradicação da pobreza, agricultura e segurança alimentar governos transparentes e responsáveis; novas tecnologias de informação e comunicação investimento na saúde (combater a AIDS); educação capacitação e desenvolvimento cultural; desenvolvimento de infraestrutura e recursos humanos; facilitação de regressos ansiados e de reassentamentos de descendentes de africanos escravizados; assistência jurídica $[\ldots]$.

165 - Insta os Estados a reforçarem a proteção contra o racismo, discriminação racial, xenofobia e intolerância correlata assegurando que todas as pessoas tenham acesso aos remédios eficazes e a gozarem do direito de se dirigirem aos tribunais nacionais competentes e em outras instituições nacionais para solicitarem reparação ou satisfações justas e adequadas, pelos danos ocasionados por tais formas de discriminação. Enfatiza ainda a importância de 
que os denunciantes vítimas de atos de racismo e discriminação racial tenham acesso à proteção da lei e aos tribunais, e chama a atenção para a necessidade de que sejam amplamente divulgados os recursos jurídicos e outros remédios legais existentes, e de que sejam de fácil acesso, rápidos e nem devem ser excessivamente complicados;

166 - Insta os Estados a adotarem as medidas necessárias, como previsto na legislação nacional, para assegurarem o direito das vítimas e obterem reparação e satisfação justas e adequadas relativas aos atos de racismo, discriminação racial, xenofobia e intolerância correlata e a formularem medidas efetivas para a prevenção da repetição de tais atos.

Observando-se o teor da declaração e do plano de ação aprovados na III Conferência, identifica-se uma linha do Direito Internacional que responsabiliza os Estados que adotaram a escravidão. Nesse caso, a fundamentação das políticas de ação afirmativas é a justiça compensatória.

Considero que essa linha assumida pelo Direito internacional rompe com um entendimento tradicional na forma de se pensar que a fundamentação das políticas de ação afirmativa na justiça compensatória seria possível apenas para os Estados que tiveram experiência com o racismo e a segregação racial previstos em leis. Esse ponto de vista pode ser percebido nas palavras do jurista Joaquim Barbosa Gomes (2001, p. $65)$ :

Em regra, somente quem sofre diretamente o dano tem legitimidade para postular a respectiva compensação. Por outro lado, essa compensação só pode ser reivindicada de quem efetivamente praticou o ato ilícito que resultou no dano. Tais incongruências, exacerbadas pelo dogmatismo outrancier típico da práxis jurídica ortodoxa, finam por enfraquecer a tese compensatória como argumento legitimados das ações afirmativas.

O rompimento com a ortodoxia da práxis jurídica apresentado na Conferência de Durban é de fundamental importância para os movimentos negros, não apenas do Brasil, mas de toda a América Latina. Sociedades em que o racismo e a discriminação racial estruturaram as relações sociais, em que pese o fato de essas sociedades não possuírem um sistema legal constituído de segregação racial.

A Conferência de Durban aponta para que o Poder Legislativo das Nações participantes do processo crie mecanismos legais que garantam a reparação, por parte dos Estados, dos prejuízos acumulados pelos negros e negras, em decorrência do racismo, da discriminação racial, da escravidão e do tráfico transatlântico. Nessa 
perspectiva, o projeto de Lei n. ${ }^{\circ}$ 3.198/2000, do então Deputado Federal Paulo Paim (PT-RS), que institui o Estatuto da Igualdade Racial, foi construído à luz da estratégia de reparação. Com efeito, a proposta apresentada por Paulo Paim encontrou muitos entraves no congresso e passou por vários processos de negociação. Enfim, foi aprovado em 20 de julho de 2010 (Lei n. ${ }^{\circ}$ 12.288).

A declaração e o plano de Ação de Durban, no que tange à reparação, parece haver se inspirado no discurso de Abdias do Nascimento. Abdias, em pronunciamento de abertura da II Plenária Nacional de Entidades Negras rumo à III Conferência Mundial contra o Racismo, Discriminação Racial, Xenofobia e Intolerância Correlata, que aconteceu no Rio de Janeiro em 11 de maio de 2001, afirma:

Uma questão fundamental nessa Conferência será das reparações. Nossa posição é que o tráfico transatlântico de africanos escravizados, o colonialismo e o racismo configuram crimes contra a humanidade os quais produziram o enriquecimento injusto dos países colonialistas e das elites dominantes brancas de sociedades multirraciais. Reconhecido esse enriquecimento ilícito, está estabelecido o direito das vítimas à reparação, que tem três componentes: compensação, restituição e reabilitação; precisamos consignar esse direito na Declaração da III Conferência; para isso, é preciso uma articulação com os países africanos, que reivindicam a reparação na forma de uma transferência de riqueza das nações ricas do Ocidente em favor dos ex-colonizados, por meio do estabelecimento de um fundo internacional e uma comissão para a distribuição das reparações. Entretanto, a proposta dos países africanos não contempla ainda as vítimas da escravatura, do colonialismo e do racismo ao outro lado do oceano. Precisamos caminhar junto com eles, apoiando sua proposta de transferência de recursos e ampliando-a para incluir como beneficiários os povos afrodescendentes e indígenas nas Américas. (Nascimento, 2002, p. 348)

Nessa perspectiva, a título de reflexão, eu pergunto: Reparação é o que falta ser feito?

\section{REFERÊNCIAS}

ARAÚJO, U. C. Reparação moral, responsabilidade pública: Direito à igualdade do cidadão negro no Brasil. In: SABOIA, G. V. (Org.). Anais do Seminários Regionais Preparatórios para a Conferência Mundial contra o Racismo, Discriminação Racial, Xenofobia e Intolerância Correlata. Brasília: Ministério da Justiça; Secretaria de Estado de Direitos Humanos, 2001. p. 315-324.

BARSTED, L. L.; HERMANN, J. Mulheres negras e indígenas: a lei e a realidade. In: BARSTED, L. L.; HERMANN, J.; MELLO, M. E. V. As mulheres e a legislação contra o racismo. Brasília: Ministério da Justiça; SEDH, 1998. p. 43-92. 
DECLARAÇÃO DE DURBAN. Documento da conferência mundial contra o racismo, discriminação racial, xenofobia e intolerância correlata. Brasília: SEPPIR, 2011.

FANON, Frantz. Pele negras máscaras brancas. Outra gente. Salvador: Editora Fator, 1983.

FISCHER, M. A etnicidade e as artes pós-modernas da memória. In: CLIFFORD, J.; MARCUS, G. A escrita da cultura: poética e política da etnografia. Rio de Janeiro: Ed. UERJ / Papéis Selvagens Edições, 2016. p. 271-321.

GOMES, J. B. Ação afirmativa e princípio constitucional da igualdade: o direito como instrumento de transformação social - a experiência dos EUA. Rio de Janeiro: Renovar, 2001.

NASCIMENTO, A. Quilombismo. 2. Ed. Brasília / Rio de Janeiro: Fundação Palmares, 2002.

ONU. Convenção Internacional sobre a Eliminação de Todas as Formas de Discriminação Racial. In: BARSTED, L. L.; HERMANN, J.; MELLO, M. E. V. As mulheres e a legislação contra o racismo. Brasília: Ministério da Justiça; SEDH, 1998. p. 121-138.

. Declaração de Durban: Declaração e Programa de ação. Brasília: SEPPIR, 2011.

SANTOS, B. S. A gramática do tempo: para uma nova cultura política. São Paulo: Cortez, 2006.

SANTOS, H. Discriminação racial no Brasil: In: SABOIA, G. V. (Org.). Anais do Seminários Regionais Preparatórios para a Conferência Mundial contra o Racismo, Discriminação Racial, Xenofobia e Intolerância Correlata. Brasília: Ministério da Justiça; Secretaria de Estado de Direitos Humanos, 2001. p. 81-102.

SILVÉRIO, R. Políticas raciais compensatórias: o dilema brasileiro do século XXI. In: SABOIA, G. V. (Org.). Anais do Seminários Regionais Preparatórios para a Conferência Mundial contra o Racismo, Discriminação Racial, Xenofobia e Intolerância Correlata. Brasília: Ministério da Justiça; Secretaria de Estado de Direitos Humanos, 2001. p. 123-138.

Recebido em janeiro de 2019 Aprovado em março de 2019 